Derecho \& Realidad

Núm. 23 • I semestre de 2014

Facultad de Derecho y Ciencias Sociales, UPTC

ISSN: 1692-3936

\title{
Principios, moral y positivismo: las respuestas $\downarrow$ redefinición del positivismo contemporáneo*
}

\author{
Principles, moral and positivism: answers and \\ redefinition of contemporary positivism
}

Jorge Luis Fabra Zamora**

\section{Resumen}

El origen de la teoría contemporánea de los principios está intentando derrocar al positivismo de Ronald Dworkin. En el presente escrito se pretende esbozar el argumento positivista frente al resto dworkiniano de la moral del derecho. Sucintamente se señalan las respuestas excluyentes e incluyentes. Son estas respuestas las que terminan por redefinir el carácter contemporáneo del positivismo jurídico.

\section{Palabras clave}

Derecho, principios, moral, positivismo jurídico.

\footnotetext{
Ponencia presentada en el IV Congreso Nacional y II Internacional de Derecho Constitucional: Los Principios en elConstitucionalismo Contemporáneo. Cartagena de Indias, Colombia, 2008.

* Egresado de la Universidad de Cartagena y director académico del Instituto de Investigaciones Jurídicas y Filosofía del Derecho "Cartagena de Indias. Correo Electrónico: jorgefabraz@gmail.com
} 


\section{Abstract}

The origin of the contemporary theory of the principles is trying to overthrow the positivism of Ronald Dworkin. In this paper is intended to outline the positivist argument against Dworkinian rest of morality of law. Briefly outlines the exclusive and inclusive responses. Are these answers, which eventually redefine the contemporary character of legal positivism.

\section{Key words}

Right, principle, moral, legal positivism. 
Los principios son uno de los ejes fundamentales de la filosofía, teoría y dogmática jurídica contemporánea. En nuestro tiempo, la reflexión sobre los principios es transversal en los estudios jurídicos y cubre todas las áreas del derecho. Prueba de esta aclamada importancia es el excelente congreso que hoy nos convoca.

Sin embargo, la extensión de la reflexión es tan grande, y sus aplicaciones son tan variadas, que podemos olvidar el origen de la reflexión en su variante contemporánea. El nacimiento de esta cuestión no es otro que el ya clásico debate de la jurisprudencia anglosajona: las críticas de Dworkin al planteamiento positivista de Hart. Dworkin, donde el primero propone la teoría de los principios como intento de derrocar al positivismo jurídico, que por sus tesis centrales -a saber, la separación entre derecho y moral o tesis de la separación y la discrecionalidad de los jueces o tesis de la discrecionalidad- nos impide "tomarnos los derechos en serio". Sin embargo, la respuesta positivista no se hizo esperar. Los juristas positivistas, deseosos de mantener la labor conceptual y descriptiva de su teoría como mejor aproximación al derecho, se hicieron sentir. No obstante, las críticas de Dworkin son fuertes y crean fuertes escollos a este intento de respuesta: ¿Cómo trataron el problema de los principios desde la perspectiva positivista? ¿Cómo lidiaron con el problema de la moralidad substantiva que los mismos conllevan y, al mismo tiempo, siguieron llamando positivista? Este el problema de la ponencia que hoy presento.

\section{El surgimiento: el alcance los principios en la crítica de Dworkin}

La reflexión de los principios la encontramos en la primera parte de la obra de Dworkin. Desde sus primeras obras demostró un descontento con la tesis de la discreción judicial (1963, p. 624-638). Por ello, en obra posterior arremetió directamente contra el positivismo, en particular contra la versión de Hart. En The Model of Rules (1968, p. 14-46), Dworkin ataca el planteamiento del derecho formulado por Hart en The Concept of $\operatorname{Law}^{1}(1961,1994)$, que entiende el derecho como una unión de reglas primarias y secundarias ${ }^{2}$. Para Dworkin, este edificio positivista se construye sobre la siguiente estructura:(1) una regla de reconocimiento, que permite el reconocimiento de las reglas, que son la base del (2) Modelo de las reglas, que es el entendimiento del derecho como la unión de reglas primarias y secundarias. Consistiendo el derecho únicamente en estas reglas, es una cuestión muy diferente de la moral, por lo cual se fundamenta, (3) una tesis de la separabilidad.

\footnotetext{
The Concept of Law. La primera edición fue publicada en 1961 y la segunda por Penélope Bullock y Joseph Raz en 1994. La primera edición castellana fue traducida por Genaro Carrió como El Concepto de Derecho, Abeledo-Prelot, Buenos Aires (1961); mientras que el Post scriptum que hace parte de la segunda fue traducido (con estudio preliminar y notas) por Rolando Tamayo y Salmoran como Post Scriptum del Concepto de Derecho, UNAM, México.

2 Vid. Especialmente, Hart $(1961,1994)$ Capítulo V.
} 
Finalmente, (4) la tesis de la discrecionalidad se basa en que los jueces tienen discrecionalidad para decir, lo que les permite la creación en los casos difíciles. Dworkin estima que este edificio se derrumba pues no puede dar cuenta de los principios. Así, amparándose en diferentes casos jurisprudenciales ${ }^{3}$ donde los jueces utilizan principios (y no reglas) para la decisión de sus casos, los estima como estándares vinculantes. Y como su contenido es, en esencia, una cuestión de moralidad, vincula el derecho con la moral. Así, en opinión de Dworkin, la tesis de Hart se cae en un efecto dominó: los principios, (1) no pueden ser reconocidos por la regla de reconocimiento ${ }^{4}$, y al ser utilizados por los jueces en sus decisiones, hacen parte del derecho, por lo cual (2) el modelo de las reglas se hace insostenible. La vinculación esencial con los principios dictados de la moralidad substantiva y su carácter "jurídico" (3) acaba con la tesis de la separabilidad. Finalmente, son estándares que (4) eliminan la discrecionalidad jurídica. En conclusión, el marco teórico proporcionado por el positivismo, debe ser desechado pues es una teoría errada sobre la naturaleza del derecho.

Para algunos como Nino, la regla de reconocimiento de Hart puede dar cuenta de los principios (s.f.). El problema entonces gira desde la existencia de los principios, a un punto superior, el debate clásico del papel de la moral en el derecho. El punto superior es que hay dos aproximaciones al concepto de derecho; una que vincula al derecho con los dictados de la moral substantiva y otra que la separa como dos cosas distintas (Coleman, 2001).

\section{Respuestas positivistas}

Aunque muchos no compartieron sus métodos, supuestos y conclusiones, Dworkin despertó la atención de los filósofos positivistas: el papel de la moral en el derecho concebido desde el positivismo. Se generó dentro del positivismo un debate sobre el modo de enfrentar las tesis dworkinianas y respaldar rl positivismo de Hart.

Un primer intento está en la tesis que ha sido denominada positivismo excluyente o positivismo fuerte, cuyo máximo exponente es Joseph Raz (1979), quien sostiene que las objeciones de Dworkin no son suficientes para modificar el positivismo, pues el problema de la autoridad es el fundamento del derecho. Su tesis básica es que la existencia y contenido de todo derecho está determinado por sus fuentes. La réplica positivista frente a los principios ha tenido dos pasos. El primero es una

3 En particular el Riggs v. Palmer y el Henninseng v. Bloomfiled Motors. El primero de estos casos fue traducido por Jorge Fabra y Carolina Guzmán y está pendiente de publicación en la Universidad Externado de Colombia.

$4 \quad$ La regla de reconocimiento es, precisamente, la que permite la identificación de las reglas válidas en un sistema determinado. 
respuesta teóricamente débil que se basa en el pedigrí: sostiene que los principios tienen pedigrí, aunque tengan otra apariencia. Por ejemplo, pueden ser "costumbres judiciales" (Carrió, 1971). Sin embargo, la verdadera respuesta exclusivista se basa en los postulados filosóficos excluyentes en la pluma de Raz: este afirma que los jueces están obligados a actuar según principios sin carácter institucional, pero son solo caracteres extrajurídicos. De esta manera, Raz diferencia la vinculación jurídica y pertenencia al derecho. Afirma que en el derecho internacional privado, en algunos casos el juez colombiano deberá aplicar derecho francés, pero este no hace parte del derecho de Colombia. En ese sentido, el derecho francés es vinculante, pero no hace parte del derecho colombiano. Análogamente, Raz afirma que la obligación de seguir principios no incorpora la moral al derecho (1971), puesto que son vinculantes, pero al no estar amparado por las fuentes (pedigrí) no hacen parte del derecho. Por ello, el uso de principios implica el ejercicio de la discreción fuerte, dado que están obligados a mirar al derecho y aplicar los principios extrajurídicos al caso en cuestión. La discreción fuerte por tanto, no representa (como afirma Dworkin) la existencia de principios que el juez es libre de aplicar si así lo desea. Más bien, los jueces están constreñidos a aplicar determinados principios, en especial, los mejores. Debemos recordar que para Raz, el derecho tiene una pretensión de autoridad legítima.

La segunda respuesta ha sido denominada incluyente o suave ${ }^{5}$. De un modo muy simple, podemos decir que esta corriente se caracteriza por sugerir que existen sistemas jurídicos cuyos criterios de validez incluyen normas morales, tales como los principios. En palabras de Hart, "la regla de reconocimiento puede incorporar como criterio de validez jurídica la conformidad principios morales o valores sustantivo", tales como cláusulas de debido proceso y dignidad humana (Waluchow). Para poder afrontar los principios -donde se considera está contenida la moral- se mantiene una afirmación modesta sobre la tesis de la separabilidad: es posible que existan sistemas jurídicos donde no se incluyen normas morales como criterios de

\footnotetext{
En 1977, año de la publicación de Taking rights seriously, surgen las dos primeras defensas del positivismo, en la cual se hacen "concesiones" a la moral: Soper y Lyons Soper, E.P. "Legal Theory and the Obligation of a Judge. The Hart/Dworkin Dispute" En: Michigan Law Review, No. 75, 1977; y, Lyons, D. "Principles, Positivism and Legal Theory", En: Yale Law Journal, No. 87, 1977) Desde 1980, Wilfred Waluchow ha analizado el modo como los principios morales pueden entrar al positivismo hartiano y ha propuesto un modelo donde la moral tiene cabida en la determinación de la juridicidad (a través de por ejemplo, el "debido proceso" o "la prohibición de tratos crueles"), que ha denominado Positivismo Jurídico Incluyente (Waluchow, Wilfred. Inclusive Legal Positivism., Oxford, Clarendon Press, 1994) En 1982, Coleman propone su modelo de incorporativismo, basado en el Positivismo Positivo y Negativo (Coleman, Jules. "Negative and Positive Positivism". En: Journal of Legal Studies, Vol. XI: University of Chicago, 1892, Coleman, Jules. "Incorporationism, Conventionality, and the Practical Diference Tesis. En: Coleman, Jules. (Ed.) Hart's Postscript Oxford: Oxford, 2001 y Coleman, Jules. The Practice of Principle: Oxford: Oxford, 2001 Segunda Parte). Finalmente, y como impulso definitivo de esta labor, en la segunda edición del Concepto de Derecho (1994), el mismo Hart dijo que esta noción era la que mejor se adaptaba a sus ideas un positivismo donde la moral tiene cabida, que le dio el nombre de positivismo suave.
} 
juridicidad; sin embargo, no hay contradicción (y podemos seguirnos llamando positivistas) si pensamos que también es posible (pero no necesario) que la regla de reconocimiento incluya criterios morales. Claro está, así como difieren en la definición de su corriente ${ }^{6}$, los representantes también discrepan en los supuestos, sentido y alcance de la moral dentro del positivismo. Además, ha tenido que soportar a numerosos críticos, dentro de los cuales está el mismo Dworkin ${ }^{7}$. Sin embargo, es de resaltar que el argumento más fuerte del positivismo jurídico incluyente para ser tenido en cuenta es que puede explicar mejor la forma en la cual funciona el derecho contemporáneo, en particular los sistemas constitucionalistas.

\section{Principios y redefinición del positivismo jurídico}

Las críticas de Dworkin y la teoría de los principios fueron los detonantes que espolearon a los positivistas jurídicos a plantear respuestas a estas objeciones (Coleman, 2001, p. 171). De este modo, el debate con Dworkin fue el que definió el nuevo carácter del positivismo jurídico (Etcheverry, 2006) y refinó su carácter general y conceptual.

El principal problema ha sido la moral y la tesis de la separación. De entrada, es difícil para un ciudadano aceptar a un pensador sostener a primera vista una teoría “amoral" (Campbell, 1996). Ningún pesador positivista serio ha dicho que la moral para Dworkin hace parte del derecho a través de los principios o que sea poco importante o periférica a la filosofía del derecho. Sin embargo, una consideración amoral está muy lejos de lo que es en realidad el positivismo jurídico. Lo central del positivismo jurídico, como afirmó John Austin, es la "simple y brillante" afirmación de que "la existencia del derecho es una cosa, su mérito y demérito es otra" (Austin, s.f.). O en la formulación de Hart, "no es una verdad necesaria que el derecho reproduzca o satisfaga determinadas demandas de moralidad, aunque de hecho comúnmente ha hecho eso" $(1961,1994)$. Los pensadores positivistas tienen una tesis conceptual (Bix, 2006), es decir, una tesis que busca determinar las condiciones para que en una sociedad podamos decir que el derecho exista (Green). Entonces, el hecho que una sociedad tenga "derecho" no depende de la presencia de determinadas estructuras de gobierno, ni de la satisfacción de ideales de justicia o democracia; sino que depende (básicamente) de unos hechos sociales y de una autoridad que guie la conducta. Sin embargo, ni los positivistas excluyentes o incluyentes se han olvidado de la importancia de la moral ${ }^{8}$. Este es otro de los mitos y malentendidos del positivismo jurídico (Gardner, 2001, p.200 ss.), que debe ir desapareciendo de nuestra cultura jurídica.

\footnotetext{
Encontramos etiquetas como incoporativismo, positivismo suave, positivismo blando, entre otras.

DWORKIN, de Law's Empire, considera que el positivismo incluyente es un convencionalismo suave, que se parece a la law-as-integrity y no merece ser denominado positivismo jurídico.

Por ejemplo, Raz (1971) afirma que la autoridad del derecho es una autoridad moral.
} 


\section{Referencias}

Austin, J. (s.f.). The Providence of Jurisprudence Determined. S.1.: s.n.

Bix, B. (2006). Jurisprudence: Theory and Context. Londres: Sweet \& Maxwell.

Campbell, T. (1996). The Theory of Ethical Legal Positivism. Dartmouth: Aldershot.

Carrió, G. (1971). Principios y positivismo jurídico. Buenos Aires: Abeledo Prelot.

Coleman, J. (2001). The Practice of Principle. Oxford: Clarendon Press.

Dworkin, R. (1963). The Judicial Discretion. The Journal of Philosophy, 60(21), 624-638.

Dworkin, R. (1968). The Model of Rules. Chicago Law Review (35), 14-46.

Etcheverry, J. B. (2006). El debate sobre el positivismo jurídico incluyente. México: Universidad Nacional Autónoma de México.

Gardner, J. (2001). Legal Positivism: 5 and 1/2 Myths. Journal of American Jurisprudence, (46), 200 y ss.

Hart, H. L. A. (1961). The Concept of Law. Oxford: Clarendon Press.

Nino, C. S. (s.f.). Introducción al análisis del derecho. Barcelona: Ariel.

Raz, J. (1979). The Authority of Law. Oxford: Clarendon Press.

Raz, J. (1971). Legal Principles and the Limits of Law. Yale Law Journal, (42). 